\section{EFFECTIVENESS OF ISOTONIC EXERCISES ON QUADRICEPS - HAMSTRING STRENGTH RATIO IN OSTEOARTHRITIC FEMALES}

\section{ABSTRAC}

OBJECTIVE

\section{MATERIAL AND METHODS}

The Quasi experimental design was selected in this study. 50 female patients With knee osteoarthritit and disturbed Quadriceps - Hamstring $(Q / H)$ ratio were

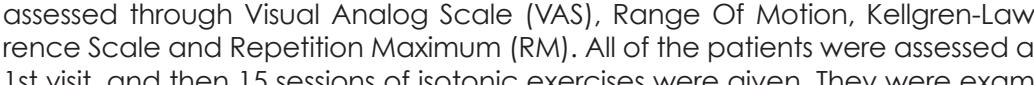
Ist visit, and then 15 sessions of isotonic exercises were given. They were exam
ined again at 15 th day to assess the effects of isotonic exercises on $Q / 4$ ratio. RESULTS

There was a significant difference in $Q / H$ ratio before and after isotonic exercises. The average $Q / H$ ratio before an exercise was less $(0.8712 \pm 0.1174)$ as
compared to the ratio taken affer exercises $(0.9832 \pm 0.1127)$. The P-value wos ess than 0.05 that was significant. The strength of quadriceps and hamstring muscles were increased, hence reduced the intensity of pain.

CONCLUSIONS

The isotonic exercises were found to be effective for strengthening of quadri-
ceps and hamstring muscles. There was a significant increase in $Q / H$ ratio after isotonic exercises, with improvement in pain and ROM. This may improve ther

glow21390@yahoo.com

\section{Nazish Rafique epetitive movements, repetitive mechanical loads and sub-groups; sex body mass and anatomy?}

Ziaudddin College of Physical Therapy nazish2312@yahoo.com

Ghazala Noor Nizam

Ziauddin College of Physical Therapy Ziauddin University
ghazi_17@hotmail.com

\section{Anum Rafique}

Physical Therapis

[Rafique N, Nizami GN, Rafique A. Effectiveness Of Isotonic Exercises On Quadriceps - Hamstring Strength Ratio In Osteoarthritic Fem
j. rehabil. 2013;2(2):15-20]

\section{INTRODUCTION}

Osteoarthritis $(O A)$ is a progressive disorder that affects he joint capsule, cartiage, synovia and subchondra occur due to destruction or degeneration of articula cartilage, bony sclerosis, sharpening of articular margins intra-articular structures, marginal lipping, bony cyst and $\mathrm{H}^{2} \mathrm{n}^{2}$. Osteocrthitis is a degenerative disease depends on many etiological factors. It is related to

Knee joint, thigh and leg muscles work together, that can assess by variety of techniques, such as visual observa tension in the knee jint muscle termed as its stren and in knee osteoarthrtis, quadriceps muscle is more prone to be affected 15.9 . Approximately $60 \%$ of the population are affected by Osteoarthritis, having the age mor pain, inflammation, decreased range of motion, stiffness, muscular weakness, especially in quadriceps (Q) and hamstring $(H)$ muscles in case of knee OA. Osteoarhritis also alters the joint proprioce

osteoarthritis, decreased muscular strength causes the progressive loss of function and joint integrity. Due to this motion 13. In osteoarthritis, gait changes observed due to misalignment of the limb and instabilities of the structures related to that particular area. Tha palient present whih limping gaif, sometimes that limping and is more common in early stage of osteorthrits. During walking and joint movement, crepitus can be

Knee complex consists of Tibiofemoral (IF). Patellofemord (PF) and Tibiofibular joints. Osteoarthritis affects all of thes in relation to the sevelty. The seventy of osteoanhitis of chists of five degees

Knee joint stability depends on its internal and externa orces with sufficient magnitude. The ability of the quadrceps muscle is to provide dynamic stablity to the kne stopped by any medicine or other, but it can be delayed hritis. Osteoarthritis of knee reduces the strength of quadriceps and hamstring muscles as well as reduces the the knee joint and hence also affects the gait pattern of an individual ${ }^{7-2}$

For the maintenance of good posture and the control of movement, during walking and during loading response
on musculoskeletal system the muscle strength plays a up from chair and also have restriction of knee rang rising heard or felt, due to the degeneration of the articular

$$
\begin{array}{ll}
1 & \text { Doubtful osteoarthritis } \\
2 & \text { Minimal osteorthrits } \\
3 & \text { Moderate osteoartis } \\
4 & \text { Severe osteoarthritis }
\end{array}
$$
(t) The proper and effective rehabilitation program is mor. key role. The muscle produces tension for the nance of posture and balance ${ }^{24}$

Ssteoarthritis of knee affects the strength of muscle or muscle of muscles. Strength is defined as the ability of muscles during the maximum effort, either dynamically or statically. Muscle strength is a complex phenomenon and including age, gender, and cross sectional area types or contraction of muscle. Muscle is the contractile part of the musculoskeletal system of the body and plays a most important role for maintaining the joint structure and joint pain². In osteoarthritis, the flexor- extensor ratio or Quadriceps-Hamstring ratio may be disturbed. That ratio equipment tested population, testing position asuing velocity of the joint and the type of the activity in which the persons are involved 4 .

The cross-sectional area of the extensor of the knee joint is knee extensors also have longer force arm distance as compared to the flexors of the knee joint. Flexors and extensors of the knee joint work together in a rhythmic knee joint movement. Therefore it is very important to maintain the strength ratio of both of those muscles. Normally, the quadriceps- hamstring ratio is 2:1 and this lexor-extensor ratio of the knee may vary between 0.4 changes and training. It is very important for the performance of targeted or purposeful movement of the body or a specticic body part in respect to the environ-

\section{METHODOLOGY}

Study Design

evaluate the effects of design was used for this study, to after treatment.

Sample Size

were included in this study with knee osteogrthritis and disturbed $Q / H$ ratio.

Study Duration
The duration of this study was seven months.

Inclusion Criteria

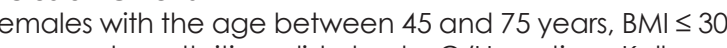
knee osteoarthritis, disturbed $Q / H$ ratio, Kellgrenand hypertension were included in this study.

Exclusion Criteria

emales having morning stiffness for more than 30 pathology traumatic injuries, deformity, any bone malignancy, infection on the skin over knee joints were excluded from this study.

Outcome Measures

This study, we measured the strength of quadriceps and and hence the $Q / H$ ratio was calculated.

Instruments

Metal weights of $2 \mathrm{~kg}$, $3 \mathrm{~kg}$ and $4 \mathrm{~kg}$, weighing machine 
were used.

Procedure
a. Isotonic Exercises

Visual Analog Scale (VAS), Range of Motion (ROM) and (6 sessions in a week) of isotonic exercises were given to them. It consisted of isotonic quadriceps exercise, straigh eg raise, short arc, hamstring strengthening and wall sets the patients. Later, it was progressed to 15-20 repetitions. Home plan of these exercises as performed in clinic, was given for 3 times per day. Patients were educated to They were examined again at day 15 to assess the effects of these isotonic exercises on $Q / H$ ratio.

\section{b. Hamstring Muscle Strength Testing}

the the couch and a towel roll was placed under the knees to prevent compression of the patella between the femu and the couch. According to the patient folerance, the patient who was then instructed to flex her knee against the resistance offered by the load. Each patien lifts the weight within their limits of pain and muscle for that patient to check the strength of muscle befor and after the isotonic exercises. The number of times the patient lifts that load through full range of motion (from knee extension to knee flexion) before getting fatigue,
was recorded as the equivalent repetition maximum (RM) of the load.

c. Quadriceps Femoris Strength Testing The isotonic quaghicets strengh was determined with the patient in a high sitting position with back support. The
load should be selected according to the patient tolerance. The metal weight was attached to the ankle, and the patient was instructed to lift the load from 900 weight within their pain limits and muscle fatigue. Tha that patient, to check the strength of muscle before and after the isotonic exercises. The number of times the patient lifted the load betore getting fatigue, from 900
flexion to full extension was recorded as the equivalen repetition maximum (RM) of the load.

\section{d. Calculation}

The for the hamstring and Quadriceps Strength The RM for the hamstrings and quadriceps of each

Repetition Maximum = RM

The above calculated RM values were taken as the isotonic quadriceps $(Q)$ and hamstring $(H)$ strength values ii. Isotonic Q/H Strength Ratio

The isotonic $Q / H$ strength ratio was calculated through following formula2:

$Q / H$ ratio $=\frac{\text { Isotonic } Q \text { strength value }}{\text { Isotonic } \text { Strength value }}$

\section{RESULT}

The general information of the patients including gender, 50 females were included in this study with the mean of 56 years. Among the single, $92 \%$ were house wives and $8 \%$ were working

\begin{tabular}{|l|c|}
\hline \multicolumn{2}{|l|}{ Table 1: General Information } \\
\hline $\begin{array}{l}\text { Age } \\
\text { (years) }\end{array}$ & $\begin{array}{c}\text { Mean } \pm \text { SD } \\
56.6 \pm 7.38\end{array}$ \\
\hline Marital Status & $\mathrm{n}(\%)$ \\
\hline Single & $2(4.0)$ \\
\hline Married & $48(96.0)$ \\
\hline Occupation & $\mathrm{n}(\%)$ \\
\hline House wife & $46(92.0)$ \\
\hline Working Women & $4(8.0)$ \\
\hline
\end{tabular}

The patients came with the presenting complains of the bilateral, unilateral right or left knees. The presence of
osteoarthritis in Tibiofemoral (TF) and Patellofemoral (PF) of that knee was examined by the x-ray. With complain in ight knee, there were $18 \%$ patients with TF osteoarthritis left knee, there were $17.1 \%$ patients with TF osteoarthritis and $12.2 \%$ patients with PF osteoarthritis. With complain in . .

\begin{tabular}{|c|c|c|}
\hline \multicolumn{3}{|c|}{ Table 2: Distribution of OA } \\
\hline Knee & $\begin{array}{c}\text { TF } \\
\mathrm{n}(\%)\end{array}$ & $\begin{array}{c}\mathrm{PF} \\
\mathrm{n}(\%)\end{array}$ \\
\hline Right & $8(18.0)$ & $5(11.6)$ \\
\hline Left & $7(17.1)$ & $5(12.2)$ \\
\hline Bilateral & $29(67.0)$ & $24(55.0)$ \\
\hline
\end{tabular}

The Average Range of Motion (ROM) of all patients was assessed at day 1. Among patients with bilateral knee osteoarthritis, right knee Active ROM (AROM) of flexion (125.750) Was less as compared to Passive ROM (PROM) terminal extension by $10.15^{\circ}$ and their PROM was 00 . While, left knee AROM of flexion (126.1\%) was less than PROM (138.790). AROM of extension shows that they had

patients with right knee osteoarthritis, right knee AROM of flexion $\left(130^{\circ}\right)$ was less as compared to PROM $\left(140^{\circ}\right)$, extension by $10^{\circ}$ and their PROM was $0^{\circ}$.

\begin{tabular}{|c|c|c|c|c|c|c|c|c|}
\hline Table 3: & Range of Motion at Day 1 \\
\hline & \multicolumn{3}{|c|}{ RIGHT KNEE } & \multicolumn{4}{c|}{ LEFT KNEE } \\
\hline & \multicolumn{2}{|c|}{ AROM } & \multicolumn{2}{|c|}{ PROM } & \multicolumn{2}{c|}{ AROM } & \multicolumn{2}{c|}{ PROM } \\
\hline Knee OA & Flexion & Extension & Flexion & Extension & Flexion & Extension & Flexion & Extension \\
\hline \multirow{2}{*}{ Bilateral } & 125.75 & 10.3 & 138.3 & 0.00 & 126.1 & 10.15 & 138.79 & 0.00 \\
& \pm 7.81 & \pm 1.21 & \pm 4.45 & \pm 0.00 & \pm 8.17 & \pm 0.87 & \pm 4.15 & \pm 0.00 \\
\hline \multirow{2}{*}{ Right } & 130.00 & 10.00 & 140.0 & 0.00 & - & - & - & - \\
& \pm 0.00 & \pm 0.00 & \pm 0.00 & \pm 0.00 & - & - & - & - \\
\hline \multirow{2}{*}{ Left } & - & - & - & - & 130.00 & 10.71 & 140.0 & 0.00 \\
\hline
\end{tabular}

Table 4: Range of Motion at Day 15

\begin{tabular}{|c|c|c|c|c|c|c|c|c|}
\hline & \multicolumn{4}{|c|}{ RIGHT KNEE } & \multicolumn{4}{c|}{ LEFT KNEE } \\
\hline & \multicolumn{2}{|c|}{ AROM } & \multicolumn{2}{c|}{ PROM } & \multicolumn{2}{c|}{ AROM } & \multicolumn{2}{c|}{ PROM } \\
\hline Knee OA & Flexion & Extension & Flexion & Extension & Flexion & Extension & Flexion & Extension \\
\hline \multirow{2}{*}{ Bilateral } & 139.7 & 0.00 & 140.00 & 0.00 & 139.7 & 0.00 & 140.00 & 0.00 \\
& \pm 1.74 & \pm 0.00 & \pm .00 & \pm 0.00 & \pm 1.74 & \pm 0.00 & \pm 0.00 & \pm 0.00 \\
\hline \multirow{2}{*}{ Right } & 140.00 & 0.00 & 140.00 & 0.00 & - & - & - & - \\
& \pm 0.00 & \pm 0.00 & \pm 0.00 & \pm 0.00 & - & - & - & \\
\hline \multirow{2}{*}{ Left } & - & - & - & - & 140.00 & 0.00 & 140.00 & 0.00 \\
& \multicolumn{7}{|l|}{} \\
* Mean \pm SD in degrees
\end{tabular}

In patients with left knee osteoarthritis, left knee AROM of
flexion (130\%) was less than PROM (140\%), AROM of extension shows that they had limited terminal extension by 1 is shown in Table 3.

The average range of motion of all patients was assessed AROM of flexion was $139.77^{\circ}$, while PROM was $140^{\circ}$, AROM and PROM of extension was 00 . Among them, left kne PROM of extension was $0^{\circ}$.

In patients with right knee osteoarthritis, right knee $A R O M$ and PROM of flexion were $140^{\circ}$, while, AROM and PROM of extension were Whe was, same values of AROM an $O A$. These results show that ROM of all patients was improved

The average muscle grading of quadriceps and hamstring muscles were examined at day 1 and day 15 , as shown in table 5. In patients with bilateral knee grading of quadriceps and hamstring muscles at day were less as compared to day 15. Among them, left knee muscle strength of quadriceps and hamstring were also

in patients with right or left knee osteoarthritis, the muscle grading of quadriceps and hamstring muscles showe
Pain assessment was done on day 1 and 15 , by using VAS
scale 0 On VAS was equivalent to 'NO Pain' $1-2$ - VAS scale was considered as mild pain, while 3-6 and 7-10 as moderate pain and severe pain respectively. Results show that pain of patients was improved after treatment. Patients with severe pain at day 1 were 14 and at day 15 having no pain, were increased from 3 to 32 (shown in

\begin{tabular}{|c|c|c|c|c|c|}
\hline \multicolumn{6}{|c|}{ Table 5: Muscle Grading } \\
\hline \multicolumn{3}{|c|}{ Assessment } & \multicolumn{3}{|c|}{ Patients with } \\
\hline 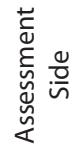 & $\begin{array}{l}\frac{\bar{u}}{\underline{\underline{m}}} \\
\sum\end{array}$ & 总 & 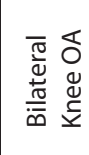 & 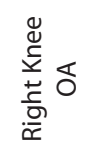 & 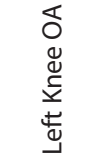 \\
\hline \multirow{4}{*}{ 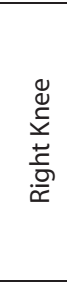 } & \multirow{2}{*}{ Quadriceps } & Day 1 & \begin{tabular}{|l|l|}
$3.02 \pm$ & 0.174
\end{tabular} & $\begin{array}{l}3.20 \pm \\
0.42\end{array}$ & - \\
\hline & & Day 15 & $\begin{array}{l}4.03 \pm \\
0.174\end{array}$ & $\begin{array}{c}4.20 \pm \\
0.42\end{array}$ & - \\
\hline & \multirow{2}{*}{ Hamstring } & Day 1 & $\begin{array}{l}3.02 \pm \\
0.174\end{array}$ & $\begin{array}{c}3.20 \pm \\
0.42\end{array}$ & - \\
\hline & & Day 15 & $\begin{array}{ll}4.03 \pm \\
0.174\end{array}$ & $\begin{array}{l}4.20 \pm \\
0.42\end{array}$ & - \\
\hline \multirow{4}{*}{ 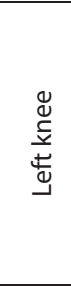 } & \multirow{2}{*}{ Quadriceps } & Day 1 & $\begin{array}{l}3.03 \pm \\
0.174\end{array}$ & & $\begin{array}{l}3.00 \pm \\
0.00\end{array}$ \\
\hline & & Day 15 & $\begin{array}{l}4.03 \pm \\
0.174\end{array}$ & & $\begin{array}{l}4.00 \pm \\
0.00\end{array}$ \\
\hline & \multirow{2}{*}{ Hamstring } & Day 1 & $\begin{array}{l}3.03 \pm \\
0.174\end{array}$ & & $\begin{array}{c}3.00 \pm \pm \\
0.00\end{array}$ \\
\hline & & Day 15 & $\begin{array}{ll}4.03 \pm \\
0.174\end{array}$ & & $\begin{array}{c}4.00 \pm \\
0.00\end{array}$ \\
\hline
\end{tabular}




\begin{tabular}{|c|c|c|}
\hline \multicolumn{3}{|c|}{ Table 6: Pain Assessment } \\
\hline Pain & $\begin{array}{c}\text { Day 1 } \\
\mathrm{n}(\%)\end{array}$ & $\begin{array}{c}\text { Day } 15 \\
\mathrm{n}(\%)\end{array}$ \\
\hline No & $0(0)$ & $32(64)$ \\
\hline Mild & $3(6)$ & $10(20)$ \\
\hline Moderate & $33(66)$ & $8(16)$ \\
\hline Severe & $14(28)$ & $0(0)$ \\
\hline
\end{tabular}

The paired T test for Q/H ratio before exercises at day $(0.87)$ was less as compared to the Test for Q/H ratio after exercises at day 15 and after exercises at day $15(0.98)$.
The P-value was less than 0.05 , which was significant This $Q / H$ ratio is shown in table 7 .

\begin{tabular}{|c|c|}
\hline \multicolumn{2}{|c|}{ Table 7: Paired T test for Q/H Ratio } \\
\hline Assessed at & (Mean \pm SD) \\
\hline Day 1 & $0.8712 \pm 0.1174$ \\
\hline Day 15 & $0.9832 \pm 0.1127$ \\
\hline *P- value $<0.05$ & \\
\hline
\end{tabular}

\section{DISCUSSION}

In this study we assessed the strengths of quadriceps and hamstring muscles in knee osteoarthritis by using
Repetition Maximum (RM) method and we found more strength in quadriceps muscle as compared to hamstring
muscle. Other studies also found lower strength of hamstring muscle groups, while quadriceps weakness is also a great risk factor for the progression of osteoarthritis.
Those studies measured muscle strength by lsotonic $\mathrm{PM}$. 10 RM method and kendall scale'.2. A study showed tha knee osteoarthritic individuals had $30 \%-50 \%$ lower muscular strength and endurance as compared to the individuals without osteoarthritis

The function of quadriceps and hamstring muscles is very with co-activation. At a time, one muscle acts concentrically and the other eccentrically3. This study
focused on isotonic exercises for muscle strong rocused on isotonic exercises for muscle strengthening
Previous studies also worked with different exercise programs and machines for the strengthening of flexor and extensor muscle groups. A study used eccentric strengthening program twice a week for 6 weeks. Other
study used moderate exercise program including isotonIc and isometric exercises and Medx $x$ maching for the strengthening of quadriceps and hamstring muscle groups ${ }^{30}$.

Isotonic strengthening exercises has great role to reduce the pain intensity and improve the daily functional activities of knee osteoarthritic patients. Previous study showed
that strengthening exercises of hamstring and quadriceps muscles enhances the functional activities like walking the pain and improves the muscle strength, muscle endurance and joint proprioception ${ }^{22}$.

This study results shows that isotonic exercises improve the the patients was improved. With improvement of pain.
ROM and muscle strength, the patients will be able to perform their activities of daily living with ease, which mprove their quality of life.

Through strengthening exercises with dietary modification we can slow the rate ef disease progression and improves
the functional activities and daily living of an individual.

The age and weight of an individual are the risk factor for As the age, weight or body mass increase, the quadriceps - hamstring ratio will necessarily be decreased. It is not possible that with the increasing body mass, the

Increased body weight of patients can put more compressive stress on their knee joints. Therefore, body weight also play role in development of $O A$ in aged increase pain: as a result muscle strength decreases. This factor might be present in patients of our study, that decreased their muscle strength and hence $Q / H$ ratio. ratio is approximately $2: 1$ in healthy individuals but in osteoarthritis this ratio becomes decreased ${ }^{28}$.

The result of this study shows that, muscle strengths are thproved after isotonic exercises and hence improved $0.05)$ which is significant, for the $Q / H$ ratio before and after isotonic exercises.

In our study, we found the significant increased in Q/H study was similar to the previous study, that is, in osteoarthritis Q/H ratio decreased to normal and through difference in that ration ${ }^{29}$. In osteon muscle is affected more than the quadriceeps muscle due to that the strengthening of hamstring are more important than quadriceps to improve the $\mathrm{Q} / \mathrm{H}$ ratio?

\section{CONCLUSION}

There was a significant difference in $Q / H$ ratio before and after the isotonic exercises. The isotonic exercises play a ey role in the strengthening of quadriceps and hamstring

\section{REFERENCE}

(1] Carvalho NA, Bittar ST, Pinto FR, Ferreira M, Sitta RR. Manual for guided home exercises for osteoarthritis Adegoke BOA Mordi EL Akinpelu OA Jaiyesimi AO. Isotonic Quadriceps-Hamstring Strength Ratios of Patients with Knee Osteoarthritis and Apparently Healthy Controls. Afr. J. Biomed. Res Weiss $E$, Jurmain contemporary review of etiology. International
Journal of Osteoarchaeology 2009;17:437-50. Coombs R, Garbuth G. Developments in the use of the hamstring/quadriceps ratio for the assessment
of muscle balance. J Sports Sci Med 2002;1 (3):56-62.

Jaiyesimi AO, Jegede J. Hamstring and quad strength ratio: Effect of age and gender. Journal of the nigeria society of physiotherapy
$2005 ; 15(2): 54-58$.

[6] Kong PW, Burns SF. Bilateral difference in hamstrings Phys Ther Sport 2010:11 (1):12-17.
[7] Kaminski TW, Wabbersen CV, Murphy RM. Concentric Versus Enhanced Eccentric Hamstring Strength Training: Clinical Implications. I Athl Train
1998:33(3):216-221.

[8] Segal NA, Torner JC, Felson D, Niu J, Sharma L, Lewis CE, Nevitt M. Effect of Thigh Strength on Incident Radiographic and Symptomatic Knee Osteoarthritis
in a Longitudinal Cohort. Arthritis Rheum in a loo9:61 (9):1210-1217.

[9] Segal NA, Glass NA, Felson DT, Hurley $M$, Yang $M$, Strength and Proprioception on Risk for Knee Osteoarthritis. Med Sci Sports Exerc 2010;42(11):2081-2088.

] Lawrence RC, Helnick CG, Arnetf FC, Deyo RA of arthritis and selected musculoskeletal disorders in the United States. Arthritis Rheum 1998:41:778-99. [11] Guccione AA, Felson DT, Anderson JJ, Anthony JM,
Zhang Y, Wilson PW. The effects of specific medical
conditions on the functional limitations of elders in the Framingham Study. Am I Public Health

12] Davis MA, Ettinger WH, Neuhaus JM, Mallon KP. Knee osteoarthritis and physical functioning:
evidence from the NHANES I Epidemiologic Follow up Study. J Rheumatol 1991;18(4):591-8.

13] Kaufman KR, Hughes C, Morrey BF, Morrey M, An KN. Gait characteristics of patients with knee osteoar-

[14] McCloskey DI. Kinesthetic sensibility. Physiol Rev 1978:58:763-820.

[15] Easton BT. Evaluation and treatment of the patien Kellgren $J$ H. Lawrence Is . Radiological Bssessment of osteo-arthrosis. Ann Rheum Dis 1957:16(4):494-502.

17] Fisher NM, Pendergast DR. Reduced muscle
function in patients with osteodthitis. Scand Rehabil Med 1997-29(4):213-21.

[18] Hall MC, Mockett SP, Doherty M. Relative impact of radiographic osteoarthritis and pain on quadriceps strength, proprioception, stafic postural sway and 2006;65(7): :855-70. sway, proprioception, and maximal voluntary quadriceps contraction in patients with knee osteo-
arthritis and normal control subjects. Ann Rheum Dis (201,60(6):612-8.

] Hurley MV. The role of muscle weakness in the

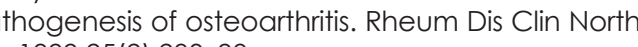
Koralewicz LM, Engh GA. Comparison of proprioception in arthritic and age-matched normal

[22] Sharma L, Pai YC, Holtkamp K, Rymer WZ. Is knee joint proprioception worse in the arthritic knee versus the unaffected knee in unilateral knee osteo-

23] Slemenda C Brondt KD. Heiman DK, Mazzuca S, Braunstein EM, Katz BP, Wolinsky FD. Quadriceps weakness and osteoarthritis of the knee. Ann Intern

and motor lerrininges to improve motor control Assessment and Treatment. 3rd Ed. Philadelelphia: FA

Davis Co Publication 1994:231. Bauman E, Drayna
Parker MG, Ruhling RO, Holt D, Bauman torque in high school football players. J Orthoo Sports Phys Ther 1983:5(1):2-6.

26] Gross MT, Credle JK, Hopkins LA, Kollin MT. Validity of tion model Phys Ther 1990:70 peak torque predict

[27] Aagaard P, Simonsen EB, Dyhre-Poulsen P. A new concept of isokinetic hamstring: Quadriceps muscle strength ratio. Am J

decline in osteoarthritis of the knee. A developing
dites hypothesis. Arthritis Care Res 1992:5(1):24-28.

[29] Hafez AR, Al-Johani AH, Zakariia AR, Al-Ahaideb A, knee osteoarthritis in relation to hamstring and quadriceps strength. I Phys Ther Sci 2013;25(11):1401-5.

30] Iwamoto J, Sato Y, Takeda T, Matsumoto H. knee: A review of the literature. World $J$ Orthop
20 2011;2(5):37-42. 